\title{
Monosodium glutamate is not associated with overweight in Vietnamese adults
}

\author{
Vu Thi Thu Hien ${ }^{1,2}$, Nguyen Thi Lam ${ }^{1}$, Nguyen Cong Khan ${ }^{3}$, Andrea Wakita ${ }^{2}$ and \\ Shigeru Yamamoto ${ }^{2, *}+$ \\ ${ }^{1}$ National Institute of Nutrition, Hanoi, Vietnam: ${ }^{2}$ Department of International Nutrition, Graduate School of \\ Humanities and Sciences, Ochanomizu University, Tokyo, Japan: ${ }^{3}$ Vietnam Food Administration Organization, \\ Hanoi, Vietnam
}

Submitted 23 February 2012: Final revision received 15 June 2012: Accepted 20 June 2012: First published online 16 August 2012

\begin{abstract}
Objective: To determine the prevalence of and associated factors for overweight, especially to determine the relationship between the intake of monosodium glutamate (MSG) as a seasoning and overweight in Vietnam.

Design: A cross-sectional survey was conducted of Vietnamese adults aged $\geq 20$ years in 2008. Dietary intake was assessed by the $24 \mathrm{~h}$ recall method for $3 \mathrm{~d}$. MSG intake was evaluated by the weighing method on three consecutive days. Physical activity was assessed based on the Global Physical Activity Questionnaire recommended by the WHO. Overweight was defined as BMI $\geq 23 \cdot 0 \mathrm{~kg} / \mathrm{m}^{2}$. Other characteristics such as age and lifelong occupation were determined by a structured questionnaire.

Setting: Some rural and urban areas of Hanoi, Thua Thien Hue Province and Ho Chi Minh City, Vietnam.

Subjects: A total of 1528 adults living in surveyed areas were randomly selected by the multistage cluster sampling method.

Results: The prevalence of overweight was $27 \cdot 9 \%$, and $81 \cdot 0 \%$ of participants were MSG users. Average MSG intake was $2 \cdot 2$ (SD 1.8) g/d. Multiple logistic regression analysis revealed that factors associated with overweight were age, region of residence, lifelong occupation, physical activity and intakes of energy, carbohydrates, saturated fat and animal protein. There was no significant association between MSG intake and overweight.

Conclusions: The study demonstrated that overweight was not associated with MSG intake in Vietnamese adults. Further longitudinal studies should be done in different populations to determine the relationship between MSG and overweight.
\end{abstract}

Even though chemical, biochemical and toxicological evaluations made by the Joint Expert Commission on Food Additives of the Codex Alimentarius Commission have shown that there is no need for establishing an Acceptable Daily Intake value for monosodium glutamate $(\mathrm{MSG})^{(1,2)}$, there is a need to conduct research on the health consequences of MSG since it has become one of the world's most widely used food additives. One of the issues of concern is weight gain related to MSG consumption. This has been a controversial problem not only in animal but also in human studies. In animal reports, it has been shown that weight gain was a result of destruction in several brain regions by high doses of MSG

$\dagger$ Correspondence address: International Nutrition, Department of Food and Nutritional Sciences, Graduate School of Human Life Sciences, Jumonji University, 2-1-28 Sugasawa, Niiza-City, Saitama 352-8510, Japan. by injection, without food and during the neonatal period $^{(3,4)}$. However, these animal studies involved doses that people are incapable of consuming. Moreover, other animal experiments have shown that there was no brain damage $^{(5)}$ or any positive association between MSG and obesity $^{(6,7)}$. In human studies, there have been controversial reports on the association between MSG consumption and obesity in different areas of China since 2008. The MSG intakes in these studies were found to range from a mean of 0.33 to $3.8 \mathrm{~g} / \mathrm{d}^{(8-10)}$. At present, overweight and obesity are increasing around the world, even in developing countries $^{(11-13)}$. In Vietnam, along with a growing economy, dietary patterns and lifestyles have changed profoundly. Consumption of meat and cholesterol-rich food has increased compared with previously, which would suggest that overweight and obesity have been increasing among the Vietnamese population ${ }^{(14-16)}$. 
In addition, the Vietnamese people have long been familiar with the L-glutamate taste from traditional fermented seasonings, such as fish sauce and soya sauce. MSG has been also used as a food seasoning to enhance the taste of foods and meals, by shaking MSG on to foods during preparation. Since there have been controversial reports concerning the association between MSG intake and overweight/obesity ${ }^{(8-10)}$, there is an urgent need to investigate this relationship in the Vietnamese population.

For these reasons, a cross-sectional survey was done to determine the prevalence of and associated factors with overweight, especially to determine the relationship between intake of MSG as a seasoning and overweight in Vietnamese adults.

\section{Materials and methods}

\section{Setting and study participants}

The study was conducted according to the guidelines laid down in the Declaration of Helsinki and it was approved by the Research and Ethical Committee of the Vietnamese National Institute of Nutrition. The survey was carried out in Hanoi, Thua Thien Hue Province and Ho Chi Minh City, which are located in the north, centre and south of Vietnam, respectively.

A multistage sampling method was used to select participants. In the first step, in each selected province/city, one commune in a rural area and one ward in an urban area were chosen randomly from the list of all communes/ wards. Second, lists of all households in the selected communes/wards were established and family codes were created. From this list, a first family was selected by randomly picking a family code. Households in which all family members usually took their meals at home and had at least one member aged $\geq 20$ years were selected for the study. All family members aged $\geq 20$ years were invited to participate in the study. Individuals were excluded if they had any of the following factors: malformation; chronic or acute disease (such as cancer or acute infection); pregnant and lactating women; or on a special diet for weight loss, weight gain, vegetarianism, salt reduction, diabetes mellitus or other reasons.

After choosing the first family, we approached other families by using the 'random walking' method to obtain 255 adults aged $\geq 20$ years (about eighty households) for each commune/ward. By this sampling procedure, a total of 1530 adults in six communes/wards were selected for participation in the survey. Written informed consent was obtained from all participants before conducting the survey.

\section{Assessment of variables}

Data were collected by trained researchers and doctors at the participant's home. In interviews and examinations, the doctors employed a specially designed questionnaire which included questions related to demographic variables (age, sex, region of residence and ethnic background), education, occupation, physical activities and lifestyle factors. Medical history of the participant was also requested.

Lifelong occupation was defined as the occupation that the participant engaged in most frequently in her/his life. It was classified as heavy worker (farmers, manual workers), office worker (office clerks and other sedentary jobs) or domestic work (housewife).

Education level was categorized into three groups by years of schooling: low level ( $\leq 5$ years), medium level (6-8 years) and high level ( $\geq 9$ years).

Body height and weight were measured while the participant was standing on a stable plane, wearing light clothing and no shoes. BMI $\left(\mathrm{kg} / \mathrm{m}^{2}\right)$ was calculated as the ratio of weight (in kilograms) to the square of height (in metres). Waist circumference was measured at the minimum circumference between the umbilicus and iliac crest, and hip circumference was measured at the widest circumference around the buttocks. Overweight was defined as BMI $\geq 23.0 \mathrm{~kg} / \mathrm{m}^{2}$ based on WHO recommendations for Asian populations ${ }^{(17)}$.

Physical activity was assessed according to the Global Physical Activity Questionnaire recommended by $\mathrm{WHO}^{(18)}$. Activity levels were categorized as low, moderate and high based on MET (metabolic equivalent of task) values.

Dietary intake was assessed by the $24 \mathrm{~h}$ recall method for three consecutive days at the participant's home, while MSG intake was evaluated by the weighing method using a precise scale on the same days. The participant was asked to eat meals prepared at home during the three survey days. On those days, a researcher came to the survey household before and after each meal. Before each meal, the researcher weighed bottles of pure MSG and any seasonings (including sauces or powder) which included MSG. After the meal, the researcher returned to the household to weigh the seasoning bottles again, and to ask the participant to recall the type and amount of any food consumed during the meal. To improve the accuracy of food descriptions, a full-size photograph album of common foods and household measures (such as bowls, cups and spoons) was used during interviews to define appropriate amounts. The participant was also asked to recall the amounts of any snacks and drinks consumed between meals.

The amount of seasonings consumed by all family members during a meal was determined by the difference between the weight of the seasoning bottles before and after the meal. The MSG content in seasonings was calculated from food labels combined with analysis. Therefore, the MSG intake of all family members was equal to the amount of seasonings multiplied by the MSG content of each seasoning. Individual MSG intake at each meal was calculated according to the MSG intake of all family members multiplied by the proportion of actual food intake of the given individual. The participant's daily 
Table 1 Characteristics of the study participants: adults aged $\geq 20$ years ( $n$ 1528) from rural and urban areas of Hanoi, Thua Thien Hue Province and Ho Chi Minh City, Vietnam, 2008

\begin{tabular}{|c|c|c|c|c|}
\hline \multirow[b]{2}{*}{ Variable } & \multicolumn{2}{|c|}{ Urban $(n 721)$} & \multicolumn{2}{|c|}{ Rural ( $n$ 807) } \\
\hline & Mean & SD & Mean & SD \\
\hline Age (years) & $45 \cdot 7$ & $15 \cdot 6$ & $45 \cdot 5$ & $15 \cdot 6$ \\
\hline $\mathrm{BMI}\left(\mathrm{kg} / \mathrm{m}^{2}\right)$ & $21 \cdot 6$ & $3 \cdot 2$ & $21 \cdot 0$ & $3 \cdot 1$ \\
\hline WHR & $0 \cdot 87$ & 0.07 & $0 \cdot 86^{*}$ & 0.07 \\
\hline \multicolumn{5}{|l|}{ Physical activity level (\%) } \\
\hline Low & \multicolumn{2}{|c|}{$49 \cdot 9$} & \multicolumn{2}{|c|}{$43 \cdot 0$} \\
\hline Moderate & \multirow{2}{*}{\multicolumn{2}{|c|}{$\begin{array}{l}18 \cdot 6 \\
31.5\end{array}$}} & \multicolumn{2}{|c|}{$16 \cdot 2$} \\
\hline High & & & \multicolumn{2}{|c|}{$40 \cdot 8$} \\
\hline Lowest education level (\%) & \multicolumn{2}{|c|}{$13 \cdot 4$} & \multicolumn{2}{|c|}{$\begin{array}{l}27 \cdot 0^{\star \star} \\
21 \cdot 6^{\star \star}\end{array}$} \\
\hline Lifelong occupation heavy worker (\%) & \multicolumn{2}{|c|}{$13 \cdot 7$} & & \\
\hline Energy intake (kJ/d) & 8226 & 2134 & $7941^{*}$ & 1937 \\
\hline Energy intake (kcal/d) & 1966 & 510 & $1898^{*}$ & 463 \\
\hline Plant protein intake $(\mathrm{g} / \mathrm{d})$ & $41 \cdot 5$ & $16 \cdot 3$ & $41 \cdot 4$ & $15 \cdot 0$ \\
\hline Animal protein intake $(\mathrm{g} / \mathrm{d})$ & $34 \cdot 2$ & $18 \cdot 8$ & $28 \cdot 2^{\star *}$ & $18 \cdot 7$ \\
\hline MSG intake (g/d) & $2 \cdot 3$ & $1 \cdot 8$ & $2 \cdot 1$ & $1 \cdot 8$ \\
\hline
\end{tabular}

WHR, waist-to-hip ratio; MSG, monosodium glutamate.

Data are presented as mean and standard deviation or percentage. Values were compared between rural and urban areas by the independent $t$ test or the $\chi^{2}$ test.

Values were significantly different from those in urban areas: ${ }^{\star} P<0.05$, ${ }^{\star \star} P<0.01$ (two-sided).

MSG intake was calculated by totalling the amount of his/her individual MSG intake at all meals for $3 \mathrm{~d}$, then dividing by three.

\section{Statistical analysis}

Data are presented as percentages or means and standard deviations. Continuous variables were $\log _{10}$ transformed if not normally distributed. Student's $t$ test (two-tailed) was applied to examine differences in age, BMI, waistto-hip ratio, energy intake and MSG intake between participants according to region of residence (rural $v$. urban). The $\chi^{2}$ test was used to examine differences in prevalence of physical activity level, education level and lifelong occupation of heavy worker between participants in rural and urban areas. Multiple logistic regression analysis was used to test several models for the associations between overweight and other variables. Data are presented as odds ratios and 95\% confidence intervals. Associations were considered statistically significant at $P<0 \cdot 05$.

All statistical procedures were performed with the statistical software package SPSS for Windows version $10 \cdot 0$ (SPSS Inc.).

\section{Results}

\section{Characteristics of participants}

Two persons refused to complete all the procedures for the study. Thus, data for 1528 adults, including 706 males and 822 females, were analysed for the present report. The mean age of participants was $45 \cdot 6$ (SD 15.6) years. As shown in Table 1 , there were no significant differences in age and BMI between urban and rural areas. Waist-to-hip ratio and energy intake in rural areas were significantly lower than in urban areas $(P<0 \cdot 05)$. Prevalence of participants with the
Table 2 Prevalence of overweight/obesity (\%) by sex and region of residence: adults aged $\geq 20$ years $(n 1528)$ from rural and urban areas of Hanoi, Thua Thien Hue Province and Ho Chi Minh City, Vietnam, 2008

\begin{tabular}{lccc}
\hline & Males & Females & Total \\
\hline Urban & $31 \cdot 1$ & $32 \cdot 4$ & $31 \cdot 8$ \\
Rural & $22 \cdot 1$ & $26 \cdot 4$ & $24 \cdot 4^{*}$ \\
Total & $26 \cdot 2$ & $29 \cdot 4$ & $27 \cdot 9$ \\
\hline
\end{tabular}

Data are presented as percentage. Values were compared between males and females, rural and urban areas by the $\chi^{2}$ test.

Value was significantly different from that in urban areas: ${ }^{\star} P<0.05$.

lowest education level was higher in rural areas than in urban areas $(P<0 \cdot 01)$, as was the prevalence of participants with a lifelong occupation of heavy worker $(P<0 \cdot 05)$.

All participants took their meals at home during the survey period, of whom $81.0 \%$ were MSG users. Average MSG seasoning intake was $2 \cdot 2(\mathrm{SD} 1 \cdot 8) \mathrm{g} / \mathrm{d}$. Therefore, glutamate (GLU) from MSG was estimated as 1.9 (SD 1.5) g/d. Average animal and plant protein intakes were $31 \cdot 0$ (SD 19.0) $\mathrm{g} / \mathrm{d}$ and $41.4(\mathrm{SD} 15 \cdot 2) \mathrm{g} / \mathrm{d}$, respectively. Thus, GLU from food was estimated to be equal to $14 \cdot 7(\mathrm{SD} 6 \cdot 7$ ) $\mathrm{g} / \mathrm{d}$. There was no significant difference between rural and urban areas with regard to MSG intake as seasoning. There were significant differences in energy intake $(P<0.05)$ and animal protein intake $(P<0 \cdot 01)$ between rural and urban areas (Table 1).

\section{Prevalence of overweight}

Table 2 shows that there was no significant difference in overweight prevalence between males and females. The prevalence was $26 \cdot 2 \%$ and $29 \cdot 4 \%$ in males and females, respectively. The prevalence in rural areas $(24.4 \%)$ was significantly lower than that in urban areas $(31 \cdot 8 \%$, $P<0 \cdot 05)$. 
Table 3 Odds ratios and $95 \%$ confidence intervals of predictors for overweight: adults aged $\geq 20$ years $(n 1528)$ from rural and urban areas of Hanoi, Thua Thien Hue Province and Ho Chi Minh City, Vietnam, 2008

\begin{tabular}{|c|c|c|c|}
\hline & OR & $95 \% \mathrm{Cl}$ & $P$ value \\
\hline \multicolumn{4}{|l|}{ Region of residence } \\
\hline Urban & 1.00 & Ref. & - \\
\hline Rural & 0.77 & $0.60,0.98$ & $<0.05$ \\
\hline \multicolumn{4}{|l|}{ Sex } \\
\hline Female & 1.00 & Ref. & - \\
\hline Male & $0 \cdot 87$ & $0 \cdot 68,1 \cdot 11$ & NS \\
\hline Age (per 1 quartile increment) & $1 \cdot 26$ & $1 \cdot 12,1 \cdot 43$ & 0.001 \\
\hline \multicolumn{4}{|l|}{ Lifelong occupation } \\
\hline Office worker & 1.00 & Ref. & - \\
\hline Heavy worker & 0.45 & $0.29,0.68$ & $<0.001$ \\
\hline Housewife & $1 \cdot 14$ & $0.83,1.57$ & NS \\
\hline \multicolumn{4}{|l|}{ Physical activity level } \\
\hline High & $1 \cdot 00$ & Ref. & - \\
\hline Moderate & $1 \cdot 20$ & $0.91,1.58$ & NS \\
\hline Low & 1.50 & $1 \cdot 08,2 \cdot 09$ & $<0.05$ \\
\hline Energy intake (per 1 tertile decrement) & 0.64 & $0.47,0.85$ & $<0.01$ \\
\hline Saturated fat intake (per 1 quartile increment) & 1.53 & $1 \cdot 33,1 \cdot 75$ & $<0.001$ \\
\hline Carbohydrate intake (per 1 tertile increment) & $1 \cdot 65$ & $1 \cdot 28,2 \cdot 12$ & $<0.001$ \\
\hline Animal protein intake (per 1 quartile increment) & $1 \cdot 20$ & $1 \cdot 06,1 \cdot 35$ & $<0.001$ \\
\hline \multicolumn{4}{|l|}{ MSG intake } \\
\hline Non-user & $1 \cdot 00$ & Ref. & - \\
\hline 1st quartile & $1 \cdot 15$ & $0 \cdot 80,1 \cdot 65$ & NS \\
\hline 2nd quartile & 0.87 & $0.56,1.35$ & NS \\
\hline 3rd quartile & 0.69 & $0.47,1.00$ & NS \\
\hline 4th quartile & $0 \cdot 88$ & $0.63,1.22$ & NS \\
\hline
\end{tabular}

MSG, monosodium glutamate; Ref. referent cetagory.

$\mathrm{OR}$ and $95 \% \mathrm{Cl}$ from multiple logistic regression analysis, model was adjusted for education level and smoking.

\section{Associated factors for overweight}

Table 3 shows results of the multiple logistic regression model applied to analyse associations between overweight and related variables. It reveals that age, region of residence, lifelong occupation, physical activity level and intakes of energy, carbohydrates, saturated fat and animal protein acted as significant predictors for overweight. There was no significant association between overweight and the intake of MSG as food seasoning. The model was adjusted for education level and smoking. Increased age was positively related to the risk of overweight $(P<0 \cdot 001)$. Participants living in rural areas $(P<0.05)$ and those whose lifelong occupation was heavy work $(P<0 \cdot 001)$ had a significantly reduced risk of overweight. Participants who did physical activity at low levels had an overweight prevalence 1.5 times higher than those who did so at high levels $(P<0 \cdot 05)$.

Reduced energy intake was associated with a significantly reduced risk of overweight $(P<0 \cdot 01)$. Increased intakes of carbohydrates, saturated fat and animal protein were separately related to a higher risk of overweight $(P<0 \cdot 001$ for all).

\section{Discussion}

The present report demonstrates that the prevalence of overweight was $27.9 \%$ in a large sample of adults living in three different regions of Vietnam. This is lower than the prevalence in Western countries and China, which ranges from 48 to $73 \%^{(19-21)}$, but similar to that in other Asian countries, which ranges from 17 to $26 \%{ }^{(22-25)}$. Concerning overweight in urban areas, the prevalence in the three regions in the current study was $31 \cdot 1 \%$ and $32.4 \%$ in males and females, respectively. These prevalences are similar to those in 2004 in Ho Chi Minh City, the largest city of Vietnam. This shows that overweight is a noteworthy problem in Vietnam, especially in urban areas.

Factors contributing to overweight and obesity have been given great attention and studied extensively ${ }^{(21,26-28)}$. Similar to previous studies, our data also found that increasing age and less physical activity are predictors of overweight $^{(21,26,27)}$. Participants who had a lifelong occupation as heavy workers had less risk of overweight than those who did not. In addition, our study confirmed the previous findings that increased intakes of energy, carbohydrates, saturated fat and animal protein were separately associated with increased risk of overweight ${ }^{(28,29)}$. We observed that the prevalence of overweight in urban areas was significantly higher than in rural areas. This can be explained by the fact that most of the participants in rural areas were farmers who had lifelong occupation as heavy workers and had energy intakes lower than those in urban areas, so they had less risk of overweight than participants in urban areas.

The present survey is the first one done in Vietnam concerning the intake of MSG as seasoning, and its major strengths are that we selected a large number of participants representative of three ecological regions of the country and that we chose an appropriate method for 
MSG measurement. The noteworthy finding was that our results contrast with those from the studies by $\mathrm{He}$ et $a l^{(8,10)}$. Even though we used nearly same method as He et al. in the latter study ${ }^{(10)}$, we could not find any significant association between MSG seasoning intake and overweight. In our survey, participants had their meals at home and the intake of MSG as seasoning was measured by the weighing method for every meal during three consecutive days; this may be a more reliable method than that used by He et al., since they assessed the amount of MSG seasoning intake by $24 \mathrm{~h}$ recall $^{(10)}$ or asked users to demonstrate the amount of MSG seasoning added during food preparation ${ }^{(8)}$. Because overweight is a multi-influenced phenotype which is related to lifestyle, environment and genome, the relationship between MSG and overweight should be considered and studied not only in China and Vietnam, but also in different populations and ethnicities.

The question whether the MSG-enhanced taste of foods can lead to increased total energy intake, thus increasing overweight, is still controversial. It is well known that Asian countries have a higher intake of seasonings rich in MSG; however, these countries do not show higher BMI, while in Western countries the MSG intake is lower but the prevalence of overweight and obesity is higher ${ }^{(24,25,30)}$. In our participants, the prevalence of overweight was higher in urban areas, while MSG seasoning intake was not significantly different between rural and urban areas. Our literature reviews also found that several studies performed with animal models show either that MSG promotes overweight $^{(31)}$ or that it has no effect ${ }^{(32)}$. In addition, a recent study with human volunteers has shown that the subjective assessment of neither hunger nor fullness was affected by MSG supplementation ${ }^{(33)}$. Regarding to physiology of GLU, 'Glutamate salts such as MSG dissociates in the neutral area so that independent from origin and salt species free GLU is formed'. Also, GLU in food and GLU from MSG are similarly metabolized in the human body ${ }^{(1)}$. Beyreuther et al. ${ }^{(1)}$ have shown that total intake of GLU from food in European countries was $5-12 \mathrm{~g} / \mathrm{d}$, while GLU in seasoning was only about $0 \cdot 4 \mathrm{~g} / \mathrm{d}$. Our study also found that GLU in seasoning was $1.9 \mathrm{~g} / \mathrm{d}$, while GLU in food was estimated to be equal to $14.7 \mathrm{~g} / \mathrm{d}$. This means that GLU from MSG is indeed small when compared with GLU in food. For these reasons, we cannot say that only MSG (but not GLU in food) causes overweight/obesity. In our study, it is not likely due to chance that we found significant associations between overweight and intakes of energy, carbohydrate, saturated fat and animal protein separately, but not between overweight and MSG seasoning intake.

Our results also support the findings from the study carried out 5 years ago by Shi et al. ${ }^{(9)}$, which found that there was no association between obesity and MSG seasoning intake in the Chinese population. However, in their study, the cut-off for overweight was BMI $\geq 25 \cdot 0 \mathrm{~kg} / \mathrm{m}^{2}$, while in the present study the cut-off was BMI $\geq 23 \cdot 0 \mathrm{~kg} / \mathrm{m}^{2}$, as defined by the WHO to identify risks of an undesirable state of health that warrants a public health or clinical intervention $^{(17)}$.

Despite being carried out in a large number of Vietnamese adults from three different areas (north, central and south), our study has several limitations. First, the survey was done in autumn and winter; therefore, dietary and MSG seasoning intake may not represent the full picture of the four seasons in Vietnam. Second, the participants in our study had meals at home; hence, adults who have meals away from home may have different characteristics from those presented in the current report. Third, due to the cross-sectional design, longitudinal studies using the same method of MSG measurement are needed to confirm our findings.

\section{Conclusions}

The present study demonstrates that the prevalence of overweight in Vietnam is relatively high compared with nearby countries. These findings suggest that overweight is becoming an alarming problem in Vietnam which requires great efforts to prevent. The associations between overweight and risk factors were assessed by using multiple logistic regression modelling. Although MSG intake was relatively high, we could not find a relationship between MSG intake and overweight. It is suggested that further longitudinal studies should be done in different populations and ethnicities to determine the association between MSG and overweight.

\section{Acknowledgements}

The study was supported by Professor Shigeru Yamamoto. All authors declare no conflict of interest. V.T.T.H. collected and analysed the data, interpreted the statistical analysis and wrote the manuscript with assistance from N.T.L. and S.Y. A.W. contributed to the writing of the paper and the literature review. N.T.L. and N.C.K. were responsible for quality control of the dietary data. S.Y. was responsible for data interpretation and all subsequent revision, as well as the financial support for the study. All authors reviewed the manuscript critically. The authors gratefully acknowledge the cooperation of all participants and the support of local authorities in each province/city. They are grateful to the staff of the Vietnam National Institute of Nutrition and local health staffs who helped in conducting the study; and thank Professor Andrew Durkin from Indiana University (Bloomington, IN, USA) for help with the manuscript.

\section{References}

1. Beyreuther K, Biesalski HK, Fernstrom JD et al. (2007) Consensus meeting: monosodium glutamate - an update. Eur J Clin Nutr 61, 304-313. 
2. Walker R \& Lupien JR (2000) The safety evaluation of monosodium glutamate. J Nutr 130, 1049-1049.

3. Bunyan J, Murrell EA \& Shah PP (1976) The induction of obesity in rodents by means of monosodium glutamate. Br J Nutr 35, 25-39.

4. Olney JW (1969) Brain lesions, obesity and other disturbances in mice treated with monosodium glutamate. Science 164, 719-773.

5. Takasaki Y (1978) Studies on brain lesions after administration of monosodium L-glutamate to mice. II. Absence of brain damage following administration of monosodium L-glutamate in the diet. Toxicology 9, 307-318.

6. Nakagawa T, Ukai K, Ohyama T et al. (2000) Effects of chronic administration of sibutramine on body weight, food intake and motor activity in neonatally monosodium glutamate-treated obese female rats: relationship of antiobesity effect with monoamines. Exp Anim 49, 239-249.

7. Kondoh T \& Torii K (2008) MSG intake suppresses weight gain, fat deposition, and plasma leptin levels in male Sprague-Dawley rats. Physiol Behav 95, 135-144.

8. He K, Zhao L, Daviglus M et al. (2008) Association of monosodium glutamate intake with overweight in Chinese adults: the INTERMAP Study. Obesity (Silver Spring) 16, $1875-1880$

9. Shi Z, Luscombe-Marsh ND, Wittert GA et al. (2010) Monosodium glutamate is not associated with obesity or a greater prevalence of weight gain over 5 years: findings from the Jiangsu Nutrition Study of Chinese adults. Br J Nutr 104, 457-463.

10. He K, Du S, Xun P et al. (2011) Consumption of monosodium glutamate in relation to incidence of overweight in Chinese adults: China Health and Nutritional Survey. Am J Clin Nutr 93, 1328-1336.

11. Deurenberg YM, Tan BY, Chew SK et al. (1999) Manifestation of cardiovascular risk factors at low level of body mass index and waist-hip ratio in Singaporean Chinese. Asia Pac J Clin Nutr 8, 177-183.

12. Ko GTC, Chan JCN, Cockram CS et al. (1999) Prediction of hypertension, diabetes, dyslipidaemia or albuminuria using simple anthropometric indexes in Hong Kong Chinese. Int J Obes Relat Metab Disord 23, 1136-1142.

13. World Health Organization (2000) Obesity: Preventing and Managing the Global Epidemic. Report of a WHO Consultation. WHO Technical Report Series no. 894. Geneva: WHO.

14. Ministry of Health \& National Institute of Nutrition (2003) National General Nutrition Survey 2000. Hanoi: Medical Publishing House.

15. Ministry of Health \& Vietnam Statistic Committee (2003) Report on National Medical Survey in 2001-2002. Hanoi: Medical Publishing House.

16. Cuong TQ, Dibley MJ, Bowe S et al. (2007) Obesity in adults: an emerging problem in urban areas of Ho Chi Minh City, Vietnam. Eur J Clin Nutr 61, 673-681.

17. WHO Expert Consultation (2004) Appropriate body-mass index for Asian population and its implications for policy and intervention strategies. Lancet 363, 157-163.
18. Surveillance and Population-Based Prevention, Department of Chronic Diseases and Health Promotion, World Health Organization (2008) Global Physical Activity Questionnaire (GPAQ). www.who.int/chp/steps (accessed January 2012).

19. James PT, Leach R, Kalamara E et al. (2001) The worldwide obesity epidemic. Obes Res 9, Suppl. 4, S228-S233.

20. Ogden CL, Carroll MD, Cutin LR et al. (2006) Prevalence of overweight and obesity in United States, 1999-2004. JAMA 295, 1549-1555.

21. Lee SA, Wen W, Xu WH et al. (2008) Prevalence of obesity and correlations with lifestyle and dietary factors in Chinese men. Obesity (Silver Spring) 16, 1440-1447.

22. Ismail MN, Chee SS, Nawawi H et al. (2002) Obesity in Malaysia. Obes Rev 3, 203-208.

23. Moon OR, Kim NS, Jang SM et al. (2002) The relationship between body mass index and the prevalence of obesityrelated diseases based on the 1995 National Health Interview Survey in Korea. Obes Rev 3, 191-196.

24. Tan CE, Emmanuel SC, Tan BY et al. (1999) Prevalence of diabetes and ethnic differences in cardiovascular risk factors. The 1992 Singapore National Health Survey. Diabetes Care 22, 241-247.

25. Yoshiike N, Seino F, Tajima S et al. (2002) Twenty-year changes in the prevalence of overweight in Japanese adults: the National Nutrition Survey 1976-95. Obes Rev 3, $183-190$

26. Zhang X, Sun Z, Zhang X et al. (2008) Prevalence and associated factors of overweight and obesity in a Chinese rural population. Obesity (Silver Spring) 16, 168-171.

27. King GA, Fitzhugh EC, Bassett DR et al. (2001) Relationship of leisure-time physical activity and occupational activity to the prevalence of obesity. Int J Obes Relat Metab Disord 25 , 606-612.

28. Hu G, Pekkarinen H, Hanninen O et al. (2002) Comparison of dietary and non-dietary risk factors in overweight and normal-weight Chinese adults. Br J Nutr 88, 91-97.

29. Chaput JP, Leblanc C, Pérusse L et al. (2009) Risk factors for adult overweight and obesity in the Quebec Family Study: have we been barking up the wrong tree? Obesity (Silver Spring) 17, 1964-1970.

30. Rhodes J, Titherley AC, Norman JA et al. (1991) A survey of the monosodium glutamate content of foods and an estimation of the dietary intake of monosodium glutamate. Food Addit Contam 8, 663-672.

31. Dawson R, Pelleymounter MA, Millard WJ et al. (1997) Attenuation of leptin-mediated effects by monosodium glutamate-induced arcuate nucleus damage. Am J Physiol Endocrinol Metab 273, E202-E206.

32. Boutry C, Bos C, Matsumoto H et al. (2011) Effects of monosodium glutamate supplementation on glutamine metabolism in adult rats. Front Biosci (Elite Ed) 3, 279-290.

33. Boutry C, Matsumoto H, Airinei G et al. (2011) Monosodium glutamate raises antral distension and plasma amino acid after a standard meal in humans. Am J Physiol Gastrointest Liver Physiol 300, G137-G145. 